\title{
Empowerment-Based Positive Youth Development: A New Understanding of Healthy Development for African American Youth
}

\author{
Raphael Travis Jr. ${ }^{1}$ \\ Tamara G. J. Leech ${ }^{2}$
}

1. Texas State University - San Marcos

2. Indiana University - Purdue University, Indianapolis

The authors wish to thank the Robert Wood Johnson Foundation New Connections Program for the generous Publication Support Grant that assisted in the preparation of this manuscript.

\begin{abstract}
A shift occurred in research about adolescents in the general population. Research is moving away from deficits toward a resilience paradigm and understanding trajectories of positive youth development. This shift has been less consistent in research and practice with African American youth. A gap also exists in understanding whether individual youth development dimensions generate potential in other dimensions. This study presents an empowerment-based positive youth development model. It builds upon existing research to present a new vision of healthy development for African American youth that is strengths-based, developmental, culture-bound, and action-oriented. It emphasizes the relationship between person and environment, the reinforcing nature of developmental assets, and the necessity of a sense of community and community engagement for youth.
\end{abstract}

This is the author's manuscript of the article published in final edited form as:

Travis, R., \& Leech, T. G. J. (2014). Empowerment-Based Positive Youth Development: A New Understanding of Healthy Development for African American Youth. Journal of Research on Adolescence, 24(1), 93-116. Available from: http://doi.org/10.1111/jora.12062 


\section{Empowerment-Based Positive Youth Development: A New Understanding of Healthy Development for African American Youth}

Aggressive, delinquent, intellectually inferior, and hypersexual dominate representations of African American men and boys in scholarship (Cassidy \& Stevenson, 2005; Hall, 2009; Matthews, Kizzie, Rowley, \& Cortina, 2010; Swinton, Kurtz-Costes, Rowley, \& OkekeAdeyanju, 2011). Sexual promiscuity, aggressiveness, delinquency, poor lifestyle choices, and consistent stress amidst stoicism dominate representations of African American women and girls in scholarship (Aronowitz \& Morrison-Beedy, 2004; Chen \& Wang, 2011; Van Ryzin \& Leve, 2012; Wilson, Woods, Emerson, \& Donenberg, 2012). These depictions seem privileged within research on health, well-being, and education outcomes of African American youth.

However, for youth in the general population, there has been a shift in empirical research toward a resilience paradigm (Leipold \& Greve, 2009). Scholars place increased emphasis on understanding trajectories of positive youth development (Bowers et al., 2010; Lewin-Bizan et al., 2010). This research indicates that a large segment of adolescents demonstrate healthy development by building upon personal and environmental strengths, even when burdened by factors that increase the risk of negative outcomes (Leipold \& Greve, 2009; Masten, 2001; Swanson, Spencer, Dell'Angelo, Harpalani, \& Spencer, 2002; Trask-Tate, Cunningham, \& LangDeGrange, 2010). One conceptual framework associated with these shifts—positive youth development (PYD) — has inspired innovative empirical questions, theoretical representations, and developmental interventions that emphasize adolescents' assets and strengths.

Positive youth development has been applied to the overall African American cultural experience and to the specific ideas of coping and resilience in the face of risk (Clark, Harris, \& Allen, 2005; Lee et al., 2011; Taylor et al., 2005). Yet, the paradigm shift has been slower among research on African American youth. Individual research efforts oscillate between optimal youth development and risk-based discussions of African American youth (Barrow, Armstrong, Vargo, \& Boothroyd, 2007; Lee et al., 2011; Swanson et al., 2002). There is a deficit in sustained research specifying the unique culture-bound dimensions of PYD trajectories among African American children and adolescents. Amidst the need for more research, frameworks depicting connections between these individual and environmental assets (dimensions) must be clear, measurable, and culturally relevant.

In this study, we begin to address this shortcoming in the literature by applying one of the most promising positive youth development frameworks-the Five Cs of positive youth development - to the experience of African American youth and adolescents. In the tradition of positive youth development, we neither stay mired in challenges nor ignore racial and ethnic dynamics (Swanson et al., 2002). Instead, we propose a modification to the existing Five Cs framework to present a new vision of healthy developmental trajectories for African American youth that is strengths-based, developmental, culture-bound, and action-oriented.

Integrating empirical research on the Five Cs with culturally specific research on common youth development goals allows us to introduce a refined framework containing seven principles. The resultant, more culturally comprehensive and empowerment-based framework is offered as a structure to (1) provide a blueprint of significant developmental pathways and personenvironment relationships for all youth, (2) identify culturally specific strengths that can augment the existing Five Cs framework, and (3) develop an empirically testable youth development model specific to African American youth. This study aims to add to scholarly 
discussions of positive features of African American adolescence that lie at the intersection of individual and community life.

\section{The Five Cs of Positive Youth Development}

The Five Cs of positive youth development is one of many frameworks for conceptualizing a core set of characteristics that intersect to denote time-specific instances of youth well-being (Bowers et al., 2010). Positive youth development is a second-order latent construct by measurement, which builds on five firstorder latent constructs (Figure 1). Analysts using data from the 4H Study of Positive Youth Development have described, operationalized, and found reliable and valid measures for the first-order latent factors: competence, character, connection, confidence, and caring (Bowers et al., 2010; Lerner et al., 2005). Their results support the hypotheses that the first-order constructs inform the higher-order latent positive youth development (PYD). Additional research within this framework indicates that youth show a greater tendency to contribute positively to self, family, community, and broader society when PYD is present in sufficient levels (Bowers et al., 2010; Lewin-Bizan et al., 2010).

The definitions of the five first-order $C$ constructs are essential for a complete understanding of PYD. Connection refers to positive and supportive bidirectional bonds with family, friends, and other proximal relationships (Lerner et al., 2005). These perceived relationships often reflect how youth are cared for, accepted, and affirmed in life. Indicators of this support have included family support, positive family communication, nonfamily adult relationships, caring neighborhoods, caring school climate, and parent involvement in schooling.

Caring and compassion, as one concept, reflects empathy, sympathy, and identification with others (Lerner et al., 2005). Davis (1983) described empathy with multiple dimensions, including awareness of other's experiences and emotional responsiveness to the awareness. The ability to be empathic and respond to distress and pain of others includes a physiological response that inhibits aggression and promotes motivation to help others (Decety, 2011). Further, how we feel about the potential targets of empathy may influence our willingness to act on it (Decety, 2011). Recent work suggests that empathy is flexible; people can overcome early-life deficits in empathy (i.e., partially and fully overcome) through modeling and new strong relationships (i.e., connections).

Character reflects attitudinal and behavioral assessments of perceived morality. We focus on attitudes (i.e., perspectives about risky behavior) and conceptualize behavior (e.g., actual risky behavior) as a more distal outcome. Using an attitudinal definition, character is morality or moral identity, attitudes about societal and cultural rules, possession of standards for correct behavior, a sense of right and wrong, and integrity (Lerner et al., 2005). Recent measurements of character also include valuing diversity (Bowers et al., 2010).

Confidence includes self-worth, self-efficacy, and one's overall self-regard, not specific to a behavior or activity (Lerner et al., 2005). In general, it captures an assessment of satisfaction regarding one's current circumstances, future possibilities, and agency. It is a correlate of selfesteem and other indicators of positive mental health. It is informative among African American youth, who have a higher-than-average percentage of youth in grades 9-12 that report being sad, unhappy, or depressed. Almost 28\% (27.7\%) of African American youth, compared with a national average of $26.1 \%$, stated that during the past year, they felt so sad or hopeless almost every day for 2 weeks or more in a row that they stopped doing some usual activities (Centers for Disease Control \& Prevention, 2011). 
Competence refers to perceived mastery across ability domains. It is often captured by beliefs about academic success and work achievement and productivity (Lerner et al., 2005), but it also applies to physical, social, and emotional competencies. The value of competencies for African American youth is often attributed to being a type of capital aiding the transition into stable and secure adult living (Swanson et al., 2002). However, research suggests it is much more.

Investigations of these Five Cs as a measure of positive youth development reveal high convergent validity. The measure relates well to other definitions of positive youth development, such as the Search Institute's developmental assets framework (Scales, Benson, Leffert, \& Blyth, 2000) and the community action framework (Gambone, Klem, \& Sipe, 2002). Similar definitions also exist for measures of SYD used in multi-contextual, neighborhood effects and resilience research described by Elliott et al. (2006).

The Five Cs model also compares substantively to a measure of positive youth development in studies of Australian adolescents (Hughes, Witherspoon, Rivas-Drake, \& West-Bey, 2009). Hawkins, Letcher, Sanson, Smart and Toumbourou (2009) developed a similarly structured second-order latent construct to capture positive development, but specific to older adolescence (Hughes et al., 2009). Their first-order constructs-life satisfaction, social competence, trust in authorities and organizations, trust and tolerance for others, and civic action and engagementultimately overlap with first-order constructs in the Five Cs model of Lerner et al. (2005). For example, Hawkins et al.'s (2009) life satisfaction construct includes indicators analogous to confidence and competence in the Five Cs model. Their social competence construct includes indicators analogous to elements of character and caring. Their trust and tolerance of others construct includes indicators reflective of connection. However, Hawkins and colleagues' civic action and engagement are within their five first-order constructs, unlike the Five Cs model. In general, Lerner et al.'s Five Cs framework shows good internal and external validity within the larger adolescent population.

A considerable research gap remains, however, regarding the empirical validity of these dimensions for youth of color. Concerns exist about the generalizability of research findings from large, but minimally diverse, national samples to young African Americans (Ginwright, Cammarota, \& Noguera, 2005). For example, the recent findings reported by Bowers et al. (2010) included only 7\% African Americans in the sample from the first six waves of the $4 \mathrm{H}$ study. It is not that positive youth development dimensions are invalid for youth of color; rather greater specification of evidence can help articulate the dimensions' relevance for their social and cultural realities. Prior literature has described the importance of targeting positive youth development research and practice toward youth of color for (1) better articulation of unique cultural dynamics influencing pathways to development and (2) better understanding of potential culturally unique manifestations of development (Lucero, 2000; Sesma \& Roehlkepartain, 2003; Swanson et al., 2002). There are various reasons to expect slippage between the existing theoretical frameworks and the person-environment transactions within unique structural realities of African American youth outlined below. This slippage or potential mismatch may be in specification of the processes that lead to positive youth development, but also in the interrelationships among them.

\section{Structural Realities and Positive Youth Development among Young African Americans}


Proponents of positive youth development strategies with African Americans are consistent in citing that a strengths-based approach is a welcome departure from negative stereotyping, risksaturated discussions, and problem-oriented objectives for working with youth (Olive, 2003; Rozie-Battle, 2002). The Five Cs approach certainly has the potential to combat these issues. However, we must simultaneously acknowledge that the Five Cs occur within an ecological context that may inhibit African American youth's optimal expression of these developmental potentialities. Structural and social realities limit the Five Cs-in its current conceptual formfrom offering a framework that (1) embraces individual and cultural strengths and (2) provides sufficiently specific pathways by which to understand developmental needs and opportunities for African American youth and communities (Washington \& Johnson, 2012). These structural challenges and theoretical limitations are the impetus for our efforts to build a more robust, empowerment-based conceptual model of the Five Cs within the African American population.

In Democracy Matters, West (2004) talks about the social reality of many African Americans from his vantage point. West laments, "Families bereft of resources and communities devoid of webs of care yield thin cultural armor against the demons of despair, dread and disappointment” (p. 26). Here, we contest the words “bereft” and “devoid” but build upon West's general allusions to specify direct challenges to the developmental infrastructure of too many African American youth, using the language of the Five $\mathrm{C}$ dimensions. A concise review of three general categories of structural barriers-socioeconomic inequality, access to resources, and institutionalization-affirms West's general statement and gives us reason to consider expanding the Five C dimensions to capture the idea of "cultural armor" as a system of strengths and developmental assets.

\section{Socioeconomic Inequality}

Race and socioeconomic status are heavily conflated by historic and present-day racial dynamics in the United States. A wealth gap is persistent between African Americans and other groups (Centers for Disease Control \& Prevention, 2011). An astounding proportion of African American children and adolescents live below the poverty line. The poverty rate for African American children in 2010 was 38.2\% (American Psychological Association, 2011). The disparate number of African American youth raised in female-headed homes compounds these statistics. Household incomes are often substantially lower when there is a single wage earner, a gender disparity in income, and a trend toward service-sector jobs, often described as factors in an overall feminization of poverty (Brady \& Kall, 2008). The poverty rate for Black children in female-headed households was 48.8\% (American Psychological Association, 2011). Absolute poverty and relative poverty, linked with income disparities, are associated with a range of undesirable outcomes including immediate and cumulative stress. Further, some research suggests that for African American youth, pressures around status consumption are high, “influencing self-esteem and self-acceptance” (Sweet, 2010). However, these strategies of avoiding social exclusion also have shown a uniquely negative physiological influence on blood pressure among low-income adolescents in comparison with higher-income adolescents (Sweet, 2010).

The persistent poverty and wealth gap that exists between African Americans and other groups also adds pressure to the mastery of functional competencies and success within education. A majority of African Americans eighteen years of age or older (82\%) completed high school. However, $18 \%$ did not, which is double the percentage of Whites (Centers for Disease Control \& 
Prevention, 2011). Educational achievement associates with future income generation and other correlates of wealth (Centers for Disease Control \& Prevention, 2011).

\section{Access to Resources}

Throughout the United States, residential segregation further concentrates the effects of poverty and undereducation. Residential segregation transforms communities as it "concentrates the advantages and disadvantages associated with race in the United States” (Bennett, 2011, p 1125). Simultaneously, it limits African American families' access to resources. African Americans are more likely to reside in lower-income communities. Lower-income communities have become more concentrated, with the proportion of low-income households in low-income communities increasing over the last 30 years (Fry \& Taylor, 2012).

Living in lower-income communities can have a range of environmental influences, including exposure to violence, environmental hazards, lower-quality institutional resources (Bennett, 2011), and limited opportunities to maintain healthy levels of nutrition and physical activity (Lewis et al., 2005). For example, African American families are more likely to live in neighborhoods with less access to grocery stores and fruit and vegetable markets (Moore \& Diez Rouz, 2006). Conversely, they have greater proximity to hazardous waste sites and the release of other toxic pollutants (Bullard, 1990). These trends are long-standing and persist today. They have limited access to healthcare centers such as hospitals and doctor's offices (Acevedo-Garcia, Lochner, Osypuk, \& Subramanian, 2003) and are provided poorer public services (Schneider \& Logan, 1982). The residents of these areas are often physically distant from businesses and industries that provide jobs and drive economic growth (Lewin-Epstein, 1986). They are even physically and socially distant from higher-income Black and White families (Fry \& Taylor, 2012; Quillian, 2002). Overall, the most prolific scholars of this topic profess that the social and economic disinvestment in these areas is multifaceted and poses severe and enduring structural limitation for youth (Massey \& Denton, 1993; Wilson, 1987).

One of the most important structural limitations is school quality. Despite school desegregation efforts, African American youth continue to attend lower-performing schools than their White peers attend (Dickens, 2005; Wiggan, 2007). There is strong evidence that the racial composition of the school is associated with educational quality. This is not to assert students cause the problems, but rather that the students learn within environments of compromised quality. Research suggests that African American students, but not White students seem more adversely affected by increases in African American enrollment (Hanushek, Kain, \& Rivkin, 2009). African American youth experience different educational contexts, which threaten school engagement and subsequent competency attitudes and beliefs. For example, African American youth are uniquely impacted by low academic expectations from teachers and staff, especially boys (Swanson et al., 2002; Wood, Kaplan, \& McLoyd, 2007), disparate school discipline policies (Fabelo et al., 2011; Losen, 2011), and perceived discrimination in school (Chavous, Rivas-Drake, Smalls, Griffin, \& Cogburn, 2008). Research consistently describes obstacles and facilitators of high engagement within a supportive well-functioning educational system and the subsequent impacts to school engagement and perceptions of academic competencies (Swanson et al., 2002; Toldson, 2008; Wimberly, 2002).

\section{Institutionalization}


African Americans continue to be overrepresented in the criminal justice system, and these elevated rates are highly skewed for young African Americans. Evidence continues to emerge highlighting the contribution of disparate school suspension and expulsion policies to involvement in the criminal justice system (Fabelo et al., 2011; Losen, 2011). Due partially to this school to prison pipeline, students of color, including African American youth, are overrepresented in juvenile detention and eventually prison (Kim \& Geronimo, 2009; Skiba, 2001). A climate of ongoing criminal justice involvement has been cultivated, from more mild suspicion and questioning to more severe arrest and conviction. For example, in New York City, in 2011, despite being 4.7\% of the city's population, African American and Latino males between 14 and 24 comprised 41.6\% of stops by law enforcement under their "stop and frisk" policy (New York Civil Liberties Union, 2012). The policy is the act of "temporarily detaining people on the street, questioning them, and possibly also frisking or searching them if police officers have suspicion of past or imminent criminal activity" (Center for Constitutional Rights, 2012). Ninety percent of those stopped were “innocent," meaning they were not issued a summons or arrested (New York Civil Liberties Union, 2012).

African American youth account for 30\% of the youth arrested in the United States; however, they only constitute $17 \%$ of the youth population (Arya \& Augarten, 2008). African American youth comprise $62 \%$ of the youth prosecuted in the adult criminal court system, and they are nine times more likely than White youth to receive an adult prison sentence (Arya \& Augarten, 2008). Each stage of the criminal justice process from arrest to sentencing includes overrepresentation by African Americans (Poe-Yamagata \& Jones, 2003).

Even young people who do not have direct contact with the prison system are indirectly affected by racial disparities in prosecution and sentencing. The incarceration rate among all individuals aged 30-34 in 2008 was 3,328 per 100,000 in 2009 (Sabol, West, \& Cooper, 2010). However, this overall number masks large racial discrepancies: 1,793 Whites, 3,446 Latinos, and 11,137 African Americans per 100,000 people were incarcerated (Sabol et al., 2010). Many of these prisoners are parents, and one study found that 809,800 of 1,518,535 inmates are parents of children under 18 (Glaze \& Maruschak, 2008). At 6.7\% of all United States' children under 18, African American children with parents in prison far outpace other groups. For instance, 46\% of all children with fathers in prison at midyear 2007 were African American (Glaze \& Maruschak, 2008).

A disproportionate percentage of African American youth also have parents who spend time committed in mental health institutions. African American adults are overrepresented in inpatient psychiatric facilities compared with their relative share of the overall U.S. population (Snowden, Hastings, \& Alvidrez, 2009). These families and youth experience more than the disruption of family structure and the stress of dealing with health issues. They also face the stigma that can accompany institutionalization and the fear and distrust that can heighten within their communities (Keating \& Robertson, 2004; Whaley, 2001). As such, enhanced chances of institutionalization and the subsequent dynamics of mass institutionalization among African American families are another distinct structural reality in the lives of African American youth.

\section{Cultural Armor and Structural Realities}

Socioeconomic status, access to resources, and institutionalization each have substantial implications for a theoretical framework of positive youth development that relies heavily upon youth's attitudes toward institutions and normative beliefs. Many of the discussed structural 
realities paired with historic inequalities create a context of risk that has led to relatively unique cultural adaptations seeking to promote resiliency and thriving among African American youth. Attitudes toward academic achievement and future economic productivity serve as one prime example of this indirect effect.

The centrality of academic beliefs to positive youth development amplifies when discussing healthy masculinity, for example, as a specific type of positive development, as dominant or traditional definitions of masculinity encompasses economic and educational superiority (Bem, 1993; Gutmann, 1997). Yet, the historic and present social circumstances faced by the African American community illustrate that these constructions, and even the association between academic success and economic productivity, may not be as culturally relevant. Due to historic circumstances and continued institutional discrimination, African American women play a central role in economic production within households (Staples, 1985). Gender attitudes related to education and economics tend to be more fluid among African Americans compared with the gender polarization in larger society (Lovejoy, 2001). This historic situation coupled with fluid gender role attitudes may result in a construction of masculinity among African American men that does not rely as heavily upon traditional economic and educational characteristics (Franklin, 1984; Majors \& Billson, 1992).

Furthermore, the difference in the meaning of education and school context may result in part from the continued conflation of race and socioeconomic status. As a group, African Americans' social and economic status often limits available structural resources, including those related to educational achievement. This structural disadvantage could weaken the perception of education, as a viable path to economic success. In other words, limited access to high-quality education may further marginalize education within African American adolescents' perceptions of legitimate opportunity structures. Therefore, when thinking of measuring competence, it is even more essential that a range of competencies are considered as valuable in addition to traditional measures of academic competency attitudes.

Finally, traditional educational attainment does not always translate into economic success at the same rate for African American and White men. According to statistics from the Census Bureau, in 2003 African American women with a bachelor's degree earn more than their White counterparts earn; however, on average, African American men with a bachelor's degree earn $80 \%$ of the salary of their White counterparts (Journal of African Americans in Higher Education, 2009). Hence, from a theoretical and a practical standpoint, educational attainment, as a developmental process or opportunity structure, may have a different meaning for African American teens. Because of all three of these considerations-gender role attitudes, continued real-world conflation of race and socioeconomic status, and the gender- or race-specific economic significance of a college degree-African American youth beliefs about academic success and economic productivity (i.e., “competence”) may be unique. Compared with other youth, it may also have less significance, except for interactions with other youth development dimensions.

This example of one strand of positive youth development can extend to other aspects of the nexus of positive youth development. For example, prior researchers examined the prevalence of nihilistic attitudes among African Americans as a toxic aspect of a culture, where confidence has been steadily eroded (Kubrin, 2006; West, 2004). Other researchers discussed how confidence and esteem strengthen from respect offered within a "cool pose culture," where fearlessness, inhibited emotion, and creative posturing buffer against pain, marginality, and unstable 
confidence (Majors \& Billson, 1992, p. 8)—particularly among African American males. These coping strategies are questionable (Hall, 2009; Majors \& Billson, 1992, p. 5), but can help to “dissipate psychological crippling influences of societal dynamics” (Hall, 2009, p. 534). In our proposed extension of the Five Cs, this type of positive cultural adaptation is more fully recognized, especially with the introduction of the community dimension. These aforementioned unique structural realities for African American youth coexist with dynamics that have the potential to impinge upon each Five $\mathrm{C}$ construct: connection, confidence, competence, caring, and character.

\section{Recursive Processes and Covariance among the Five Cs}

Next, it is necessary to consider how the described contextual mismatch translates to a conceptual model that allows interactions among youth development dimensions. The discussion above makes it clear that the social, economic, and racial context of many African American youth conflates many of the individual core competencies within the Five Cs model. However, interrelatedness among the Five $\mathrm{C}$ dimensions supports the concept of youth as assets for communities, replete with their own strengths to build upon. Single dimensions generate potential in other dimensions, creating opportunities for exponential developmental growth instead of additive growth. Alternately conceptualized, these recursive processes (Yeager \& Walton, 2011) can augment existing cultural armor (West, 2004) of African American adolescents. These reinforcing assets can facilitate resilience amidst adversity and create optimal pathways to individual and community well-being.

Immediate and long-term outcomes apply to this model. Reinforcing assets at one time point influence developmental potential at subsequent time points. For example, the idea of developmental cascades were examined by Lewin-Bizan et al. (2010), focusing on the long-term interactions among parenting, self-regulation, and positive youth development. Jelicic, Bobek, Phelps, Lerner and Lerner (2007) and Bowers et al. (2010) examined longitudinal effects, but recursive processes among latent constructs of positive youth development were not included.

The standard scholarly depiction of the Five Cs exists with limited direction on how the concepts relate to each other, only specifying shared error variance as depicted in the latent construct by Jelicic et al., 2007) and Bowers et al. (2010); see Figure 2. We introduce theory-based recursive processes among the Five Cs, with connection as the core of this nexus of indicators of positive youth development (Figure 2). Substantial research supports statistically significant relationships among youth development dimensions (Table 1). Some variable pathways are robust with supporting evidence (e.g., connection to competence), while others are sparser (e.g., connection to confidence). Figure 2 (Models 1 and 2) capture the interplay between the two major recursive processes in our current formulation: moral identity and mastery. Moral identity (Figure 2, Model 1) extends the premise of character to capture the synergy between connection, caring, and character, whereas mastery (Figure 2, Model 2) extends the premise of competence to capture the synergy between connection, confidence, and competence.

\section{Moral Identity: Connection, Caring, and Character}

In that they represent one larger concept, each element of the Five Cs is critical to every other developmental dimension within the model. According to the available evidence in the literature, there is a particularly symbiotic relationship between connection, caring, and character. Together, the direct and indirect interactions between these three elements promote the 
development and maintenance of what can be understood as moral identity (Figure 2, Model 1). Emerging evidence on the merit of confidence for morals also exists. For example, confidence relates to character, where adolescent self-efficacy is associated with attitudes toward deviance (Nebbitt \& Lombe, 2008).

Indicators of caring covary with the presence of positive connections. From a developmental standpoint, strong attachment security (connection) has shown to strengthen empathic reactions (caring) (Shaver \& Mikulincer, 2011). At the same time, connections-young people's ability to sustain positive bonds with peers, teachers, and other supportive adults - influence empathy and prosocial decision making (Hurd, Zimmerman, \& Xue, 2009; Yancey, Grant, Kurosky, KravitzWirtz, \& Mistry, 2011). The social aspect of empathy based on connection is reinforced by research on the influence of social network density and positive network valence on adolescent empathy (Wolfer, Cortina, \& Baumert, 2012).

Caring, or empathy, is also directly related to moral reasoning and behavior (i.e., character), with more empathic adolescents reporting greater moral maturity (Belgrave, Nguyen, Johnson, \& Hood, 2011; Humphries \& Jagers, 2009). Neural networks offer new evidence for the malleability of empathy, including identification of time-specific triggers of increased empathy, and empathy as a precursor to altruism and prosocial behavior (Decety, 2011). Other notable aspects of empathic flexibility include people's ability to overcome early life deficits in empathy and that feelings about potential targets of empathy may influence the willingness to act on empathy (Decety, 2011).

Finally, connection and character reinforce each other. Wallace (2002) finds that youth highly involved with parents and peers (connection) who have a strong disapproval for delinquency are more likely to have similarly negative attitudes toward substance use and delinquency (character). The value of strong, positive relationships is most evident within risky contexts, thus promoting resilience through the ability to overcome adversities (Hurd et al., 2009; Prelow, Bowman, \& Weaver, 2007). In sum, the qualities inherent to caring and character produce what is commonly understood as morality, and this morality is at the same time dependent upon and a determinant of the connections that produce a moral identity.

\section{Mastery: Connection, Confidence, and Competence}

We see mastery as a set of reinforcing assets_connection, confidence, and competence (Figure 2, Model 2) - that aid in the transition to stable and secure adult living (Lee et al., 2011; Swanson et al., 2002). Research linking connection, confidence, and competence suggests recursive processes among these PYD dimensions that significantly influence skill development and mastery. For example, increased social support from parents and peers (connection) is significantly associated with increased self-esteem (confidence) (Gaylord-Harden, Ragsdale, Mandara, Richards, \& Petersen, 2007). Among a sample of African American high school girls, social support from parents (connection) buffered exposure to risk and promoted ego resiliency (Trask-Tate et al., 2010). Ego resiliency includes confidence, and the additional elements of "meaningful and active engagement in the world, a sense of mastery within several life domains" (Trask-Tate et al., 2010, pp 170-171). Support from fathers and grandparents was statistically significant. These findings have added significance based on statistics suggesting the importance of greater father involvement and the higher prevalence of grandparents as caregivers among African American youth. 
Similarly, increased confidence predicts several youth development dimensions including academic competence (Murry, Berkel, Brody, Chen, \& Miller, 2009; Toldson, 2008). Simply feeling good about life is an important predictor of academic success (Toldson, 2008). Low academic confidence is also associated with low emotional support from peers, parents, or other adults (Cunningham \& Swanson, 2010; Denson, 2003).

Evidence specific to African American youth indicates that maintaining supportive positive relationships is more important than maintaining a particular family structure (Roberts, Lewis, \& Carmack, 2011). Academic success most consistently links to the quality of existing connections (Hurd et al., 2009; Somers, Owens, \& Piliawsky, 2008; Toldson, 2008). Going a step further, youth with family involvement in education and academic interventions, and with supportive positive relationships between parent and youth (connection), are significantly more likely to report academic competence (Bailey \& Bradbury-Bailey, 2010; Hanushek et al., 2009).

The overwhelming proportion of literature on adolescent competence concentrates on educational competence. However, research attention exists for positive youth development through other competencies, including vocational achievement and other employment and workforce competencies (Bowers et al., 2010). For example, when youth report feelings of hopelessness (confidence), anger, and alienation (connection), they are much more likely to report unemployment (Gibbs \& Bankhead, 2000). Similarly, an association exists between support structures, that is "a support network that is consistent, compassionate, and challenging" (connection), and workforce success for youth involved in the juvenile justice system (Brown, Maxwell, DeJesus, \& Schiraldi, 2002, p. 34).

Mastery transcends "good grades" and is a collection of reinforcing markers that together are the necessary ingredients for developing and executing many skills at any given moment, but also for being a lifelong learner. An adolescent will benefit from having a strong architecture for mastery across many dimensions of his or her life, but it is particularly valuable for transitioning into adulthood as successful and self-sufficient students or professionals.

\section{Amplifying Recursive Processes: Community and Citizenship}

Sense of community and active and engaged citizenship are two new constructs to integrate with the aforementioned Five Cs model of positive youth development. Within the general population, the relevance of these constructs is found in models such as the Circle of Courage model of youth empowerment. In the Circle of Courage model, belonging, mastery, independence, and generosity are "shared values that must exist in any community to create environments that ultimately benefit all" (Freado, 2012). Further, applied initiatives such as Be Me or African American Male Engagement by the James L. Knight Foundation (connection and community) and the Black Youth Project initiated by Dr. Cathy Cohen (community and citizenship) sustain attention on promoting existing individual and cultural strengths of African American youth and young adults. These initiatives, if effective, can help youth connect and identify with a strong, positive, and supportive African American community. Youth that increase their sense of community and become more engaged citizens can reinforce their moral identity and mastery [recursive] processes.

These sixth and seventh $C$ additions result in a new, culturally specific empowerment-based positive youth development (EMPYD) model. It manifests as an interactive, empowerment-based identity and relationships-driven youth development model with seven interrelated dimensions. 
Empowerment links community and citizenship as "the process by which adolescents develop the consciousness, skills and power necessary to envision personal or collective wellbeing and understand their role within opportunities to transform social conditions to achieve that wellbeing” (Travis, 2013). The new community and citizenship dimensions of PYD are represented in the model similar to the core Five Cs with direct and indirect relationships with other dimensions in the model. The new hypothesized relationships, based on the introduction of community and citizenship, exist throughout current research (see Table 2, Models 3-5). A visual representation of the full nexus of developmental relationships and recursive processes in the EMPYD model is in Figure 2, Model 5.

\section{Belonging to a Masterful Community: Sense of Community and Mastery}

A meaningful community can reinforce and enhance the developmental value of mastery, which is again the integration of connection, confidence, and competence. A sense of community for adolescents involves feeling a part of "a readily available, supportive, and dependable structure" (Evans, 2007), where they feel a sense of membership, influence, a fulfillment of needs, and a shared emotional connection (Chavis, Lee, \& Acosta, 2008). Social identity theory and the associated sense of community theory capture heightened manifestations of the value of social relationships (Stets \& Burke, 2000). Sense of community also has an explicit element that highlights the value of being empowered within that community of interest (Evans, 2007). These concepts are salient for African American youth that must regularly negotiate identity and sense of belonging psychologically and socially during their transition into adulthood (Cote, 1996, 2000; Craig-Bray, Adams, \& Dobson, 1988; DeGruy, Kjellstrand, Briggs, \& Brennan, 2011; Portes \& MacLeod, 1996).

Identifying with and belonging to a community can be invaluable to the development of mastery at a given point in time, as well as longitudinally (Yeager \& Walton, 2011). However, even more important is how a strong sense of community can amplify mastery, as highlighted in recent research:

As students study and learn, and build academic skills and knowledge, they are better prepared to learn and perform well in the future. As students feel more secure in their belonging in school and form better relationships with peers and teachers, these become sources of support that promote feelings of belonging and academic success later. When students achieve success beyond what they thought possible, their beliefs about their potential may change, leading them to invest themselves more in school, further improving performance and reinforcing their belief in their potential for growth. As students do well, they are placed in higher-level classesgateways that raise expectations, expose them to high-achieving peers, and improve subsequent academic opportunities

(Yeager \& Walton, 2011, p. 286).

\section{Racial or ethnic group as community}

An often-prioritized community of identity for African American youth is cultural, based on race and ethnicity. Disentangling and quantifying the perceived meanings of and influences of racial and ethnic identity among African American youth has been an active area of research for a substantial period of time (Davis \& Stevenson, 2006; Phinney, 1992; Sellers, Smith, Shelton, Rowley, \& Chavous, 1998). Researchers of youth and adolescent development seek to describe 
the complexities of this identity through multiple dimensions; that is, they try to quantify the uniqueness of being a young African American living within present-day United States who feels a part of the historical and present-day experiences that coexist with that status. Researchers suggest that the main progenitors of cultural identity tend to be parents and mentors as socializing agents (Hurd, Sanchez, Zimmerman, \& Caldwell, 2012).

Slightly different definitions exist for racial identity, ethnic identity, and cultural identity, but each captures perceptions of a social identity linked to being a part of the African American community within the United States. One of the more commonly used measures of racial identity is the multidimensional model of racial identity (MMRI) (Sellers et al., 1998). Researchers have investigated the presence and influence of four dimensions of identity. The four dimensions (using the MMRI and correlates such as the Multidimensional Inventory of Black Identity) include the following: (1) the centrality of race to one's identity, (2) public and private regard held for the racial group, (3) the salience of race to one's identity, and (4) the ideology associated with the identity (Caldwell, Zimmerman, Bernat, Sellers \& Notaro, 2002; Hurd et al., 2012; Settles, Navarrete, Pagano, Abdou, \& Sidanius, 2010). Although racial identity and sense of community are distinct constructs that do not overlap, the conceptual connections are apparent (Chavis et al., 2008; Evans, 2007):

- Sense of membership: individuals make investments; they know others and are known as members (centrality).

- Influence: individuals exert personal influence within community and note the influence of community on others (public and private regard).

- $\quad$ Reinforcement of needs: individuals share similar values, needs, and goals with community members (ideology).

- Shared emotional connection: individuals emphasize the importance of the community and active involvement now and in the future (salience or private regard).

Racial identity and its conceptual correlates (i.e., ethnic identity and cultural identity) have been investigated for potential positive relationships to desirable psychological and social outcomes, including Five $\mathrm{C}$ constructs. For example, youth with stronger ethnic identity levels have shown significantly higher self-esteem (Mandara, Gaylord-Harden, Richards, \& Ragsdale, 2009; Travis \& Bowman, 2012). Barrow et al. (2007) used existing literature as a basis for theorizing about the value of interventions to promote resilience through strong family and social connections, self-efficacy (confidence), and ethnic identity for African American adolescents. Cultural identity is also associated with increased academic engagement and performance (competence) (Neblett, Chavous, Nguyên, \& Sellers, 2009; Smalls, 2009). Brown, Linver, Evans, and DeGennaro (2009) found that only cultural values and heritage subscales were associated with increased grades for African American young men and not women. Perhaps these stronger identities help transcend contextual barriers and stigmas associated with education.

Manifestations of racial or ethnic identity often emerge from relationships that include those with positive and supportive adults (connection) and competence. For example, results of a study of 374 African American students between Grades 7 and 12 suggest that ethnic identity, parental support, and self-efficacy are the strongest predictors of future education orientation (Kerpelman, Eryigit, \& Stephens, 2008). Similarly, a significant relationship was found between having "natural mentors" (i.e., positive and supportive adults) and educational attainment (Hurd et al., 2012, pp 1201-1202). These results occurred via increased racial identity and perceived importance of education. In the nomenclature of the present study model, these results suggest 
that sense of community is associated with connection, confidence, and competence, known collectively as our mastery dimensions.

\section{Racial, ethnic, and cultural socialization: between connection and community}

Racial, ethnic, and cultural identity can strengthen during adolescence, via socialization by parents (Cote, 1996; Craig-Bray et al., 1988; Humphries \& Jagers, 2009; Portes \& MacLeod, 1996). Hughes et al. (2009) describe "ethnic-racial socialization as the transmission of messages to children about ethnicity, race and the meaning of their group membership, including pride, history, traditions, awareness of discrimination and appreciation of diversity" (Humphries \& Jagers, 2009, p.112). Parental racial and cultural socialization mediates the relationship between connection to parents and sense of belonging to a racial or cultural community, if youth embrace their parents' socializing intent.

Parents and guardians have shown variability (i.e., high levels vs. low levels) in their socialization of children about race and ethnicity (Humphries \& Jagers, 2009; Neblett et al., 2009). However, more research is needed to determine potential variability in levels of cultural identity across levels of parental cultural socialization. The direction of socialization is likely related to identity, with the assumption that level of youth exposure translates to awareness and embracing the identity at a corresponding level (Humphries \& Jagers, 2009, p. 114). However, the consistency of this relationship is unknown, and distinctions among dimensions of socialization add to the complexity. Lastly, this is not the sole contributor to cultural identity.

Researchers distinguish between multiple dimensions of race- and ethnicity-oriented socialization, recognizing two major types of socialization: (1) protection and preparation for societal barriers and (2) personal and cultural pride (Humphries \& Jagers, 2009; Neblett et al., 2009). The first type of socialization has been more consistently associated with raising awareness of between-group differences, social stratification, and societal discrimination (Brown et al., 2009; Humphries \& Jagers, 2009). The second type of socialization is often linked to increasing awareness of cultural heritage and values, while promoting cultural engagement and pride (Brown et al., 2009; Humphries \& Jagers, 2009).

Although multiple dimensions of socialization exist in research, an inadequate amount of research exists to explain the distinct influences of preparation versus pride forms of socialization on outcomes (Humphries \& Jagers, 2009). When distinguished from one another, Humphries and Jagers (2009) found more negative outcomes (lower esteem, lower ethnic affirmation, antisocial behavior) associated with increased preparation for bias, and more positive outcomes (self-esteem, ethnic identity, academics, and behavior) linked to increased cultural pride and heritage. Similarly, increased discrimination socialization has linked to a greater sense of helplessness (Davis \& Stevenson, 2006).

When combining socialization dimensions, racial and ethnic socialization is associated with PYD dimensions competence, confidence, caring, connection, and character. Perceptions of academic success are significantly associated with racial and ethnic socialization, as well as measures of confidence (Murry et al., 2009). Robertson (2004) similarly discovered a connection between racial socialization and academic achievement. Increased cultural socialization has been associated with increased esteem and lower lethargy (Davis \& Stevenson, 2006). Additional research supports links between racial-ethnic socialization and positive youth development outcomes via esteem (confidence) (Humphries \& Jagers, 2009; Rodriguez, Umaña-Taylor, 
Smith, \& Johnson, 2009). Racial or ethnic identity is likely the mediator of relationships between socialization and these other youth development dimensions (Humphries \& Jagers, 2009; Hurd et al., 2012). Overall, the constellation of research results suggest that positive and supportive adults (i.e., parents or natural mentors) may nurture a stronger sense of identity through socialization - whether based on race, ethnicity, or culture - an identity that buffers societal stigmas and promotes stronger educational attitudes, engagement, and achievement.

Notably, other research has shown a relationship between racial and ethnic socialization and less desirable outcomes. For example, some youth that received increased racial socialization messages held attitudes that were more favorable about delinquency (Wallace, 2002; Wilson, Foster, Anderson, \& Mance, 2009). A number of explanations may exist for undesirable outcomes. First is the aforementioned multidimensionality of the concept, where "positive" socialization messages may not be additive and preparation messages crowd out pride messages. Further, parents may be providing information that seems confusing to youth. Parents or mentors may also promote a hypersensitivity to racial and ethnic issues that causes anxiety (Brown et al., 2009). Parents may prime the development-inhibiting effects of perceived discrimination. Finally, less desirable results may signal weak parental ethnic or cultural identities, where parents themselves have a poor sense of heritage, resilience, values, and cultural pride; parental messages may lack potency despite their prevalence.

\section{Limitations of a Masterful Community}

The challenge for measuring, understanding, and ultimately intervening to optimize a "masterful community" for African American youth remains in interpretations of types of socialization and identity. Although the transmission of parents' worldviews about race and ethnicity sounds straightforward, as does the assumption that positive is favorable, interpretations may vary. First, many gaps in information exist. Although prevalence, content, and frequency are commonly described in research, often missing are the onset and recency of messages, what is considered most useful, the range of sources, the perceived usefulness of messages, and the actual behaviors linked to socialization — such as the distinguishing between verbal and nonverbal communication (Lesane-Brown, Brown, Caldwell, \& Sellers, 2005).

Next, when defining racial socialization for empirical purposes, significant ambiguity remains. For example, parents may convey the same preparation or discrimination messages, but youth may interpret the messages differently (Nebbitt \& Lombe, 2008). Messages may be discouraging or inspiring. For example, African American youth without a strong sense of cultural identity may strive toward greater assimilation and stray from it being a central feature of identity. However, these youth may also be more vulnerable to perceived discrimination, lacking an active buffer to experiences whether real or imagined. Among youth reporting more discrimination, those less likely to endorse commonalities with ethnic minority groups (cultural identity) were less engaged in school (competence) and had more behavioral problems (Smalls, White, Chavous, \& Sellers, 2007). Among African American adolescents of both genders, high perceptions of collective and institutional discrimination are linked to lower self-esteem and life satisfaction (confidence) (Seaton \& Yip, 2009).

Despite these instances of concern, sense of community and the cultural pride element of identity among African Americans are strong constructs to consider within healthy positive youth development. Further, racial and ethnic identity may or may not be a prioritized community 
among some African Americans. However, evidence is consistent that this recursive mastery dimension (i.e., connection, community, confidence, competence) is often significant for youth.

\section{Belonging to a Moral Community: Sense of Community and Moral Identity}

Existing research already acknowledges the potential benefits of a strong sense of community on development and the strengthening processes related to a youth's moral identity. For example, Ward (1995) emphasizes racial and ethnic socialization as potential inhibitions to violence and crime within African American communities. Earlier work with African American adolescents by Humphries, Parker, and Jagers (2000) examined sense of community via the concept of communalism and found significant relationships between communalism and empathy (caring). The study also found a significant relationship between communalism and moral reasoning (character) for boys, but not for girls. Empathy, in turn, mediated the relationship between communalism and moral reasoning for boys. In a later study, the author replicated this design and achieved some similar results, finding that African American adolescents ascribing to greater communalism were significantly more empathic (Humphries \& Jagers, 2009). However, empathy did not mediate communalism and moral reasoning.

Hart, Atkins, and Ford (1998) explicitly discuss the concept of moral identity as self-consistent commitment to lines of action benefiting others. Although their measure of moral identity was less robust and focused on the behavioral outcome of volunteerism, the full model of predictors and outcome pathways was conceptually rich and had volunteerism influenced by moral goals or judgment and one's relationship to their social environment. For example, they discuss how "the formation of a moral identity is made easier if adolescents can explore lines of moral action, if they are supported in these explorations by relationships with persons they respect” (Hart et al., 1998, p. 519) (connection to character and also connection to caring). They continue by introducing the value of opportunities within the context of community.

Whereas some identity-forming opportunities like sports activities may be explored without institutional affiliations, we suspect that moral identities-like academic identities and artistic identities - may require the adult and community support that is commonly found in organized social institutions. (Hart et al., 1998, p. 519)

Data supported the model. Personality and family environment predicted voluntary service years later (which they described as moral identity), along with opportunities via attachment to institutional groups such as teams and clubs. In a crosswalk with our present model, their results show linkages among family support (connection and community), emotional regulation and healthy social relationships (character and connection), opportunities from teams and clubs (community), and contribution to the broader community (citizenship). Their measurement model did not include all elements of the theoretical framework. However, results suggest several recursive pathways relevant to development and maintenance of an ongoing moral identity. In sum, existing theoretical and empirical literature provides reason to believe that a sense of community is important for positive youth development among African American youth. A sense of community runs parallel to the Five Cs already recognized in the model. It also reinforces the recursive relationships we refer to as mastery and moral identity. When considering race or ethnic identity as a prioritized community, an explicit recognition exists to the potential benefits and risks associated with racial or ethnic socialization, and racial, ethnic, and cultural identity among African American youth. This concept may be important to the 
validity of the PYD model in this population and may serve as one of the links between active and engaged citizenship and many of the elements of the PYD model.

\section{Active and Engaged Citizenship: Not Just an Outcome}

Civic engagement, discussed in our present model as active and engaged citizenship, can be a valuable outcome of positive youth development (PYD) because it is a critical component of democratic societies (Flanagan \& Levine, 2010; Lerner et al., 2005). It is the action element of empowerment and the EMPYD model. As mentioned earlier, Hughes et al. (2009) consider citizenship a first-order construct within positive development. We further modify conceptualization of citizenship at the first-order level and argue that civic engagement can also influence other dimensions of PYD. For example, caring may increase with the competencies associated with a comprehensive understanding of need, justice, equity, and a sense of personal agency using talents and skills to influence the positive well-being of others (Martinez, Penaloza, \& Valenzuela, 2012, p. 480). Youth in schools with a higher academic track also report higher levels of empathy, which correlates with prior research demonstrating the same relationship (Wolfer et al., 2012). Youth reporting higher levels of achievement and educational success (competence) are also more likely to be civically engaged (Crocetti, Jahromi, \& Meeus, 2012; Eckstein, Noack, \& Gniewosz, 2012; Flanagan \& Levine, 2010). Active and engaged citizenship has the most extensive connections to the core developmental constructs of sense of community and connection (Figure 2, Model 5).

To define active and engaged citizenship, we follow the suggestions of Zaff, Boyd, Li, Lerner and Lerner (2010) and consider the developmental relevance of this civic engagement. Active and engaged citizenship is multi-dimensional, transcending common behavior-only assessments. It includes a sense of civic duty, civic skills, civic connection, and civic participation. This multidimensional account of citizenship exemplifies the need to look at developmental interrelatedness of constructs. Duty, skills, connection, and participation are relevant to each of the other PYD constructs, although some of these relationships are mediated by sense of community.

An immediate connection exists between a strong sense of community and one type of engaged citizenship pertinent to African American youth: resistance to the oppression of valued communities (Plescia \& Herrick, 2008). The opportunity to enact social change is of particular value to, but not unique to, African American youth who may be coping with structural realities of socioeconomic inequality, disparate access to resources, and overrepresentation within detention and mental health institutions (Delgado \& Staples, 2008; Gambone, Yu, Lewis-Charp, Sipe, \& Lacoe, 2004). A 2010 survey of 160 youth organizing groups found that the most common social change campaign and community issues speak directly to remediating structural challenges: educational justice (65\%), racial justice (50\%), environmental justice (38\%), health (37\%), juvenile justice (36\%), immigration rights (34\%), and gender or women issues at 30\% (Torres-Fleming, Valdes \& Pillal, 2011).

Positive citizenship development and actions have been associated with ethnic socialization, peer and parental civic attitudes and behaviors, and active supports and opportunities throughout childhood (Flanagan \& Levine, 2010; Schmid, 2012). Social network-driven pathways to engagement also exist, including peers, school-based community service, community-based youth organizations, higher education, the military, and social media-driven engagement (Flanagan \& Levine, 2010; Schmid, 2012). Each is a potential “community” within which youth 
may "feel at home” and embrace an active and engaged social identity. Social justice and activism-linked citizenship are also associated with a sense of belonging to a perceived marginalized community; however, this civic engagement may also result from a strong connection to another civically engaged individual.

In a reversal of the causal direction, civic engagement for ethnic minority youth can also spur socio-political development and critical awareness. Organizing principles usually have the objective of creating "the kind of world they want to be a part of" (Flanagan \& Levine, 2010, p. 160). Through this mechanism, there is evidence of a relationship between civic engagement and recursive relationships that make up moral identity (Ginwright, 2003; Kirshner, Strobel, \& Fernandez, 2003; Sherrod, Flanagan, \& Youniss, 2002). Further, civic engagement is most likely to reinforce moral identity if trustworthy individuals (connection or community) lead engagement efforts and if they believe actions will have a genuine impact on others (Flanagan \& Levine, 2010; Hart et al., 1998).

Acknowledging this feedback loop between engagement and constructs of PYD differs from other youth development and empowerment-based models. For example, Wagaman (2011) introduces the social empathy framework, which is a useful heuristic for understanding the value of empathy in leading youth toward greater awareness and action for social change. However, the present model provides specific measurable pathways of development that may mediate this relationship cross-sectionally and over time. The present model also identifies mechanisms for exponential growth as opposed to additive growth. Finally, these pathways offer guidance for a range of opportunities to build on existing strengths of African American youth including the critical life-course health development ingredient of mastery.

\section{Opportunity Structures for Active and Engaged Citizenship}

Martinez et al. (2012) offer an excellent civic engagement model explaining how the relationship between the individual and socializing environments promotes growth in individual and collective identity. Personal development and civic commitment occur through civic experiences and relationships and have implications consistent with the discussed constructs of moral identity (sensitization to others' realities and raised consciousness) and mastery (agency and action strategies). Awareness of social inequities and discrimination alone without the opportunity to address these inequities may be development inhibiting (Davis \& Stevenson, 2006). A sense of empowerment through experiences and relationships to help change perceived inequities in the status quo can buffer against poor esteem, depression, and other negative responses (Davis \& Stevenson, 2006; Travis \& Bowman, 2012).

The willingness and opportunity to work toward correcting injustice and changing developmentinhibiting environments are critical advances in positive youth development for African American youth, but also for many youth that identify as members of a marginalized group (e.g., women and girls, immigrants, and low-income, incarcerated or formerly incarcerated, racial or ethnic minorities). This increased agency helps individuals move from helplessness or complacency to resiliency and ultimately an agent of change (Delgado \& Staples, 2008; Watts \& Guessous, 2006).

However, Zaff, Malanchuk and Eccles (2008) argued that simply encouraging greater participation in the community was insufficient. They recommended a systematic process for ensuring that environments are consistently civic-enhancing contexts that promote contribution 
to the broader community. Consistent peer influences, parent modeling, cultural strategies, and organization-based organizing groups for civic engagement are important in early adolescence, late adolescence, and young adulthood (Shah, 2011; Zaff et al., 2008). Ginwright (2010) discusses the importance of a civic engagement pipeline for a movement of ongoing social change that includes youth leadership opportunities, postsecondary education, and employment to sustain civic engagement for youth and adults (Ginwright, 2010; Shah, 2011). Connection and community are critical pieces of this pipeline to meet community need:

[Youth] develop a sense of purpose in their lives, and see themselves as part of something meaningful and bigger than themselves. Youth also develop a sense of belonging to a family or community of people they trust.

(Ginwright, 2010, p. 9)

\section{Discussion}

Ensuring health and well-being over the life-course for all youth must include awareness of existing success stories of optimal positive development. Next, broad-based commitment must exist to maximizing these health trajectories for our youth. The present study reviews existing research providing evidence of successful developmental processes for young African Americans at the individual level and points of advantage for organizing improvements at the environmental level. This constellation of reinforcing developmental processes offers a healthier vision of wellbeing, an empowerment-based picture of positive youth development that connects individuals and communities.

This EMPYD model posits optimal positive youth development within communities that reinforce morals and mastery where positive, supportive relationships and opportunities for engaged citizenship are the norm. Present study findings are consistent with qualitative research about "what is needed" to best help young African Americans: values and behavior (akin to character), adults for guidance (akin to connection and sense of community), successful organizations (attention to structural realities), economics and systems (attention to structural realities), and stable quality parenting (connection) (Washington \& Johnson, 2012). Present study findings also reinforce how positive youth development is a function of individual potential and environmental opportunities. Again, this PYD can be (1) a time-specific aggregate of developmental strengths and (2) a strengths-driven process of working with youth to facilitate empowerment and well-being (Damon, 2004).

An emphasis on aggregate and multi level influences in this study has given us insight into core, structural reasons for fewer instances (according to these models) of positive youth development among some samples of African American youth compared with other youth (Bennett, 2011; Boardman \& Alexander, 2011; Moore \& Diez Rouz, 2006; Schott Foundation, 2008). The wellbeing of young African Americans has been associated with the quality of environmental surroundings since the first arrival of African slaves to the shores of the Caribbean and the United States. Awareness of environmental challenges is not new. Further, we acknowledge these findings as important and empirically sound, but they often problematize African American youth and their environments, truncate existing strengths and avenues of opportunity within families, schools, and communities, and minimize attention to the ability to change. Identification of the structural impediments to development is helpful because it highlights connections among developmental competencies for African American youth (Losen, 2011). 
However, the constructive potential of these connections, interplays, and indirect effects on resilience and optimal youth development has not been fully explored within the African American context (Losen, 2011; Swanson et al., 2002). The current, popular, and academic discussion about a postrace America (Bonilla-Silva, 2006; Haney-Lopez, 2010; Steele, 2008) has the potential to obfuscate theoretical "growth opportunities" within scholarship on the development of African American youth. We must ensure continued focus on not only the symbiotic relationship between ecological contexts and African American youths' positive development, but also the way we conceptualize and study this relationship.

Optimal fit between a person and his or her environment, where individual strengths are matched with sufficient levels of support and opportunities, has shown potential benefits for individuals and their communities (Delgado \& Staples, 2008; Eccles \& Gootman, 2002; Jelicic et al., 2007; Lewin-Bizan et al., 2010; Phelps et al., 2009; Scales et al., 2000). Individuals benefit through mastery, confidence, and prosocial relationships, among other things. Communities benefit from youth who are engaged and active as citizens. These youth are valued with high expectations and given opportunities to use their talents and strengths in meaningful and tangible service to their respective communities.

\section{A Blueprint for Healthy Development}

\section{Connection Is Critical}

The present EMPYD model demonstrates that connection exists at the heart of critical developmental processes that help shape young African Americans' moral identity and sense of mastery. From the earliest caregiver relationships to contemporary peer, teacher, and community relationships, these "connections" can be supportive prosocial mentors, role models for attitudes and behaviors, and doorways to the mastery of critical life skills. For example, a teacher is not an educational ATM machine to withdraw information. A teacher can fulfill a critical developmental role and facilitate the ability for youth to engage educational material and become lifelong learners. These relationships of "connection" must be valued and supported so that they can be developed or sustained wherever they exist.

\section{More Than a Mentor and More Than a Program}

Mentoring, education, and employment programs are relationship-based experiences and must be developmental in their focus. Development, health, and well-being are experience-driven. A mentor, like a teacher, and like an educational or employment program can vary in levels of quality. Although access to mentoring and relevant programs can be a formidable challenge in its own right, it is not sufficient to make access to these programs the sole outcome. Educational initiatives, mentoring, and other out-of-school time programs must incorporate programming criteria that explicitly highlight how positive youth development outcomes are recursive, activity driven, and influenced by developmental assets.

\section{Community-Driven}

A young person's sense of community is especially important for its potential to amplify empowering or risky pathways related to their moral identity and sense of mastery. For example, a full school environment that leaves a student feeling alienated and that they do not belong can sabotage the efforts of a highly engaging, exceptionally effective individual classroom teacher. 
We recognized the structural barriers of socioeconomic inequality, differential access to resources, and institutionalization as challenges to the developmental infrastructure of too many African American youth. Specifically, these challenges threaten sources of empowering interpersonal connections, a sense of community, and development-enhancing activities and experiences. However, the value of connection, one's sense of community, or developmental experiences does not diminish. Prosocial, supportive relationships and social networks must be critical components of any youth-related experience, programming, or service.

Communities and interest groups that youth prioritize should not only be recognized, they should be reinforced. Adults must make these spaces available. These communities may be a team, outof-school time program, hobby or interest group, identity-based program (by race or ethnicity, gender, sexual identity, or geography), health related program, educational program, employment program, or simply a youth-friendly space. Older African American adolescents and young adults also have fraternities, sororities, and historically Black colleges and universities that offer culturally enhanced opportunities to reinforce a sense of community and cultural identity.

Within the educational sector, innovations like project-based learning and learning communities reflect elements of the value of activity-driven communities within which students can connect, belong, learn, and contribute. Similarly, employment-related programs like YouthBuild thrive on their ability to create a sense of community and belonging for participants, which reinforced other development-enhancing program strategies (Abrazaldo et al., 2009). Finally, positive experiences in valued communities can also be the impetus for youth to reinvest their own energy into sustaining the quality of these environments when opportunities exist for active and engaged citizenship.

\section{Promising Practices}

Relationships between developmental processes and outcomes highlight what is exciting about contemporary models and practice strategies that are deliberate about incorporating African and African American culture. Promising practices that align with recursive processes described in this study include the following: culture-based rites of passage programs (Blumenkrantz \& Goldstein, 2010; Gilbert, Harvey, \& Belgrave, 2009), the culturally responsive intergenerational solidarity framework (Waites, 2009), social-belonging interventions in education (Walton \& Cohen, 2011), and the culturally responsive hip hop-based therapeutic program Beats, Rhymes, and Life, Inc. (http://brl-inc.org/overview). Each considers setting quality, but simultaneously speaks to individual growth within youths' surrounding developmental contexts of family, school, and community.

\section{Future Research}

Future research can help continue exploration and testing of the relevance of these concepts to the lived reality of young African Americans. First, the validity of the present EMPYD model may be measured by including each of these constructs within a structural equation model, allowing simultaneous testing of each conceptualized pathway. The full model can be tested against empirical data. An extension of this research can also test invariance of the model fit over time. A second branch of research can investigate results across populations. For example, differences in how pathways manifest can be examined across gender, age, and race or ethnicity. Finally, triangulating data would be optimal. For example, youth self-reports about connection 
are valid. However, adding parent and teacher perceptions of student connection and other developmental areas may allow a more robust composite for measuring dimensions.

A new era of health and well-being for young African Americans now exists. Truly positive youth development for African American youth must occur with equal parts vision, ongoing evaluation, and commitment to action. First, it is necessary to revisit our vision of empowerment-based positive youth development for African American youth, free of the shackles of a deficit or problem orientation. Next, a data-driven framework for measuring pathways to these desired outcomes is critical for research and practice. Finally, broad-based commitment must be realized for this vision, where strategies to positively influence these pathways are the norm not the exception. 


\section{References}

Abrazaldo, W., Adefuin, J., Henderson-Frakes, J., Lea, C., Leufgen, J., Lewis-Charp, H., et al. (2009) Evaluation of the YouthBuild youth offender grants. Washington, DC: U.S. Department of Labor.

Acevedo-Garcia, D., Lochner, K., Osypuk, T., \& Subramanian, S. (2003). Future directions in residential segregation and health research: A multilevel approach. American Journal of Public Health, 93, 215-221.

American Psychological Association (APA). (2011). Effects of poverty, hunger, and homelessness on children and youth. Arlington, VA: American Psychological Association.

Aronowitz, T., \& Morrison-Beedy, D. (2004). Resilience to risk-taking behaviors in impoverished African American girls: The role of mother-daughter connectedness. Research in Nursing and Health, 27, 29-39.

Arya, N., \& Augarten, I. (2008). Critical condition: African-American youth in the justice system.

Washington, DC: Campaign for Youth Justice. Retrieved February 1, 2011, from http://www.modelsforchange.net/publications/210

Bailey, D., \& Bradbury-Bailey, M. (2010). Empowered youth programs: Partnerships for enhancing postsecondary outcomes of African American adolescents. Professional School Counseling, 14, 64-74.

Barrow, F., Armstrong, M., Vargo, A., \& Boothroyd, R. (2007). Understanding the findings of resiliencerelated research for fostering the development of African American adolescents. Child and Adolescent Psychiatric Clinics of North America, 16, 393-413.

Belgrave, F., Nguyen, A., Johnson, J., \& Hood, K. (2011). Who is likely to help and hurt? Profiles of African American adolescents with prosocial and aggressive behavior. Journal of Youth and Adolescence, 40, 1012-1024.

Bem, S. (1993). Is there a place in psychology for a feminist analysis of the social context? IV. Feminism and Psychology, 3, 230-234.

Bennett, P. (2011). The relationship between neighborhood racial concentration and verbal ability: An investigation using the institutional resources model. Social Science Research, 40, 1124-1141.

Blumenkrantz, D., \& Goldstein, M. (2010). Rites of passage as a framework for community interventions with youth. Global Journal of Community Psychology Practice, 1, 41-50.

Boardman, J., \& Alexander, K. (2011). Stress trajectories, health behaviors, and the mental health of black and white young adults. Social Science and Medicine, 72, 1659-1666.

Bonilla-Silva, E. (2006). Racism without racists: Color-blind racism and the persistence of racial inequality in the united states. Lanham, MD: Rowman and Littlefield.

Bowers, E., Li, Y., Kiely, M., Brittian, A., Lerner, J., \& Lerner, R. (2010). The five Cs model of positive youth development: A longitudinal analysis of confirmatory factor structure and measurement invariance. Journal of Youth and Adolescence, 39, 720-735.

Brady, D., \& Kall, D. (2008). Nearly universal, but somewhat distinct: The feminization of poverty in affluent western democracies, 1969-2000. Social Science Research, 37, 976-1007. 
Brown, T., Linver, M., Evans, M., \& DeGennaro, D. (2009). African-American parents' racial and ethnic socialization and adolescent academic grades: Teasing out the role of gender. Journal of Youth and Adolescence, 38, 214-227.

Brown, D., Maxwell, S., DeJesus, E., \& Schiraldi, V. (2002). Barriers and promising approaches to workforce and youth development for young offenders. Baltimore, MD: Annie E. Casey Foundation. Bullard, R. (1990). Dumping in Dixie: Race, class, and environmental quality. Boulder, CO: Westview Press.

Caldwell, C., Zimmerman, M., Bernat, D., Sellers, R., \& Notaro, P. (2002). Racial identity, maternal support, and psychological distress among African American adolescents. Child Development, 73, 13221336.

Cassidy, E., \& Stevenson, H. (2005). They wear the mask: Hypervulnerability and hypermasculine aggression among African American males in an urban remedial disciplinary school. Journal of Aggression, Maltreatment and Trauma, 11, 53-74.

Center for Constitutional Rights. (2012). Stop and frisk: The human impact. New York, NY: Center for Constitutional Rights. Retrieved January 6, 2013, from http://stopandfrisk.org/

Centers for Disease Control \& Prevention. (2011). CDC health disparities and inequalities report - United States, 2011. Morbidity and Mortality Weekly Report, 60(Suppl.), 1-114.

Chavis, D., Lee, K., \& Acosta, J. (2008, June). The Sense of Community (SCI) Revised: The reliability and validity of the $\mathrm{SCl}-2$. Paper presented at the 2 nd International Community Psychology Conference, Lisboa, Portugal.

Chavous, T., Rivas-Drake, D., Smalls, C., Griffin, T., \& Cogburn, C. (2008). Gender matters, too: The influences of school racial discrimination and racial identity on academic engagement outcomes among African American adolescents. Developmental Psychology, 44, 637-654.

Chen, X., \& Wang, Y. (2011). Is ideal body image related to obesity and lifestyle behaviours in African American adolescents? Child: Care, Health and Development, 38, 219-228.

Clark, R., Harris, A., \& Allen, W. (2005). After-school youth programs: how they affect black male development and educational progress. Challenge, 11, 1-37.

Cote, J. (1996). Sociological perspectives on identity formation: The culture-identity link and identity capital. Journal of Adolescence, 19, 417-428.

Cote, J. (2000). Identity studies: How close are we to developing a social science of identity? An appraisal of the field. Identity: An International Journal of Theory and Research, 6, 3-25.

Craig-Bray, L., Adams, G., \& Dobson, W. (1988). Identity formation and social relations during late adolescence. Journal of Youth and Adolescence, 17, 173-187.

Crocetti, E., Jahromi, P., \& Meeus, W. (2012). Identity and civic engagement in adolescence. Journal of Adolescence, 35, 521-532. 
Cunningham, M., \& Swanson, D. (2010). Educational resilience in African American adolescents. The Journal of Negro Education, 79, 473-487.

Damon, W. (2004). What is positive youth development? The Annals of the American Academy of Political and Social Science, 591, 13-24.

Davis, G., \& Stevenson, H. (2006). Racial socialization experiences and symptoms of depression among African American youth. Journal of Child and Family Studies, 15, 303-317.

Davis, M. (1983). Measuring individual differences in empathy: Evidence for a multidimensional approach. Journal of Personality and Social Psychology, 44, 113-126.

Decety, J. (2011). The neuroevolution of empathy. Annals of the New York Academy of Sciences, 1231, 35-45. doi:10.1111/j.1749-6632.2011.06027.x

DeGruy, J., Kjellstrand, J., Briggs, H., \& Brennan, E. (2011). Racial respect and racial socialization as protective factors for African American youth. Journal of Black Psychology, 38, 395-420.

Delgado, M., \& Staples, L. (2008). Youth-led community organizing. New York, NY: Oxford University Press.

Denson, E. (2003). The relationship between stress, coping resources, and academic achievement in African American urban youth. Dissertation Abstracts International Section A: Humanities and Social Sciences, 63(11-A), 3851.

Dickens, W. (2005). Genetic differences and school readiness. The Future of Children, 15, 55-69.

Eccles, J., \& Gootman, J. (2002). Community programs to promote youth development. Washington, DC: National Academies Press, National Research Council.

Eckstein, K., Noack, P., \& Gniewosz, B. (2012). Attitudes toward political engagement and willingness to participate in politics: Trajectories throughout adolescence. Journal of Adolescence, 35, 485-495.

Elliott, D., Menard, S., Rankin, B., Elliott, A., Wilson, W., \& Huizinga, D. (2006). Good kids from bad neighborhoods: Successful development in social context. New York, NY: Cambridge University Press.

Evans, S. (2007). Youth sense of community: Voice and power in community contexts. Journal of Community Psychology, 35, 693-709.

Fabelo, T., Thompson, M., Plotkin, M., Carmichael, D., Marchbanks, M. III, \& Booth, E. (2011). Breaking schools' rules: A statewide study on how school discipline relates to students' success and juvenile justice involvement. New York, NY: Council of State Governments Justice Center; Public Policy Research Institute. Retrieved from http://justicecenter.csg.org/resources

Flanagan, C., \& Levine, P. (2010). Civic engagement and the transition to adulthood. Future of Children, 20, 159-179.

Franklin, C. (1984). Black male-black female conflict: individually caused and culturally nurtured. Journal of Black Studies, 15, 139-154. 
Freado, M. (2012, January 7). The circle of courage philosophy. Retrieved January 7, 2012, from http://www.reclaiming.com/content/about-circle-of-courage

Fry, R., \& Taylor, P. (2012). The rise of residential segregation by income. Washington, DC: Pew Research Center.

Gambone, M., Klem, A., \& Sipe, A. (2002). Finding out what matters for youth: Testing key links in a community action framework for youth development. Philadelphia, PA: Youth Development Strategies, Inc.; Institute for Research and Reform in Education.

Gambone, M. A., Yu, H. C., Lewis-Charp, H., Sipe, C. L., \& Lacoe, J. (2004). A comparative analysis of community youth development strategies. Medford, MA: Center for Information and Research on Civic Learning and Engagement.

Gaylord-Harden, N., Ragsdale, B., Mandara, J., Richards, M., \& Petersen, A. (2007). Perceived support and internalizing symptoms in African American adolescents: Self-esteem and ethnic identity as mediators. Journal of Youth and Adolescence, 36, 77-88.

Gibbs, J., \& Bankhead, T. (2000). Joblessness and hopelessness: The case of African American youth in South Central Los Angeles. Journal of Ethnic and Cultural Diversity in Social Work: Innovation in Theory, Research and Practice, 9, 1-20.

Gilbert, D., Harvey, A., \& Belgrave, F. (2009). Advancing the Africentric paradigm shift discourse: Building toward evidence-based Africentric interventions in social work practice with African Americans. Social Work, 54, 243.

Ginwright, S. (2003). A conceptual model: Impact of youth organizing on youth. Los Angeles, CA: Youth Organizing Workshop.

Ginwright, S. (2010). Building a pipeline for justice: Understanding youth organizing and the leadership pipeline. Occasional papers series on youth organizing number 10. Brooklyn, NY: Funders' Collaborative for Youth Organizing.

Ginwright, S., Cammarota, J., \& Noguera, P. (2005). Youth, social justice, and communities: Toward a theory of urban youth policy. Social Justice, 32, 24-40.

Glaze, L., \& Maruschak, L. (2008). Parents in prison and their minor children. Washington, DC: Bureau of Justice Statistics.

Gutmann, M. (1997). Trafficking in men: The anthropology of masculinity. Annual Review of Anthropology, 26, 385-409.

Hall, R. (2009). Cool pose, black manhood, and juvenile delinquency. Journal of Human Behavior in the Social Environment, 19, 531-539. doi:10.1080/10911350902990502

Haney-Lopez, I. (2010). Post-racial racism: Racial stratification and mass incarceration in the age of Obama. California Law Review, 98, 101-148.

Hanlon, T., Simon, B., O'Grady, K., Carswell, S., \& Callaman, J. (2009). The effectiveness of an afterschool program targeting urban African American youth. Education and Urban Society, 42, 96-118. 
Hanushek, E., Kain, J., \& Rivkin, S. (2009). New evidence about Brown v. Board of Education: The complex effects of school racial composition on achievement. Journal of Labor Economics, 27, 349-383.

Hart, D., Atkins, R., \& Ford, D. (1998). Urban America as a context for the development of moral identity in adolescence. Journal of Social Issues, 54, 513-530.

Hawkins, M., Letcher, P., Sanson, A., Smart, D., \& Toumbourou, J. (2009). Positive development in emerging adulthood. Australian Journal of Psychology, 61, 89-99.

Hughes, D., Witherspoon, D., Rivas-Drake, D., \& West-Bey, N. (2009). Received ethnic-racial socialization messages and youths' academic and behavioral outcomes: Examining the mediating role of ethnic identity and self-esteem. Cultural Diversity and Ethnic Minority Psychology, 15, 112-124.

Humphries, M., \& Jagers, R. (2009). Culture: A possible predictor of morality for African American adolescents. Journal of Research on Adolescence, 19, 205-215.

Humphries, M., Parker, B., \& Jagers, R. (2000). Predictors of moral reasoning among African American children: A preliminary study. Journal of African American Psychology, 26, 51-64.

Hurd, N., Sanchez, B., Zimmerman, M., \& Caldwell, C. (2012). Natural mentors, racial identity, and educational attainment among African American adolescents: Exploring pathways to success. Child Development, 83, 1196-1212.

Hurd, N., Zimmerman, M., \& Xue, Y. (2009). Negative adult influences and the protective effects of role models: A study with urban adolescents. Journal of Youth \& Adolescence, 38, 777-789.

Jelicic, H., Bobek, D., Phelps, E., Lerner, R., \& Lerner, J. (2007). Using positive youth development to predict contribution and risk behaviors in early adolescence: Findings from the first two waves of the 4$\mathrm{H}$ study of positive youth development. International Journal of Behavior Development, 31, 263-273.

Journal of African Americans in Higher Education (JBHE). (2009). African American student college graduation rates remain low, but modest progress begins to show. Retrieved February 1, 2011, from http://www.jbhe.com/

Keating, F., \& Robertson, D. (2004). Fear, black people and mental illness: A vicious circle? Health \& Social Care in the Community, 12, 439-447.

Kerpelman, J., Eryigit, S., \& Stephens, C. (2008). African American adolescents' future education orientation: Associations with self-efficacy, ethnic identity, and perceived parental support. Journal of Youth and Adolescence, 37, 997-1008.

Kim, C., \& Geronimo, I. (2009). Policing in schools: Developing a governance document for school resource officers in K-12 Schools. New York, NY: American Civil Liberties Union.

Kirshner, B., Strobel, K., \& Fernandez, M. (2003). Critical civic engagement among urban youth. Penn GSE Perspectives on Urban Education, 2, 1-20.

Kubrin, C. (2006). "I see death around the corner": Nihilism in rap music. Sociological Perspectives, 48, 433-459. 
Langenkamp, A. (2010). Academic vulnerability and resilience during the transition to high school: The role of social relationships and district context. Sociology of Education, 83, 1-19.

Lee, F., Lewis, R., Sly, J., Carmack, C., Roberts, S., \& Basore, P. (2011). Promoting positive youth development by examining the career and educational aspirations of African American males: Implications for designing educational programs. Journal of Prevention and Intervention in the Community, 39, 299-309.

Leipold, B., \& Greve, W. (2009). Resilience: A conceptual bridge between coping and development. European Psychologist, 14, 40-50.

Lerner, R., Lerner, J., Almerigi, J., Theokas, C., Phelps, E., \& Bobek, D. (2005). Positive youth development, participation in community youth development programs, and community contributions of fifth-grade adolescents: Findings from the first wave of the 4-H study of positive youth development. Journal of Early Adolescence, 25, 17-71.

Lesane-Brown, C., Brown, T., Caldwell, C., \& Sellers, R. (2005). The comprehensive race socialization inventory. Journal of Black Studies, 36, 163-190.

Lewin-Bizan, S., Lynch, A., Fay, K., Schmid, K., McPherran, C., Lerner, J. V., \& Lerner, R. M. (2010). Trajectories of positive and negative behaviors from early- to middle-adolescence. Journal of Youth and Adolescence, 39, 751-763.

Lewin-Epstein, N. (1986). Effects of residential segregation and neighborhood opportunity structure on the employment of black and white youth. Sociological Quarterly, 27, 559-570.

Lewis, L., Sloane, D., Nascimento, L., Diamant, A., Guinyard, J., Yancey, A., \& Flynn, G. (2005). African Americans' access to healthy food options in south Los Angeles restaurants. American Journal of Public Health, 95, 668-673.

Livingston, J., \& Nahimana, C. (2006). Problem child or problem context? An ecological approach to young black males Reclaiming Children and Youth, 14, 209-214.

Losen, D. (2011). Discipline policies, successful schools, and racial justice. Boulder, CO: National Education Policy Center.

Lovejoy, M. (2001). Disturbances in the social body: Differences in body image and eating problems among African American and white women. Gender \& Society, 15, 239-261.

Lucero, M. (2000). The spirit of culture: Applying cultural competency to strength-based youth development. Denver, CO: Assets for Colorado Youth.

Majors, R., \& Billson, J. (1992). Cool pose: The dilemmas of Black manhood in America. New York, NY: Simon \& Schuster.

Mandara, J., Gaylord-Harden, N., Richards, M., \& Ragsdale, B. (2009). The effects of changes in racial identity and self-esteem on changes in African American adolescents' mental health. Child Development, 80, 1660-1675. doi:10.1111/j.1467-8624.2009.01360.x 
Martinez, M., Penaloza, P., \& Valenzuela, C. (2012). Civic commitment in young activists: Emergent processes in the development of personal and collective identity. Journal of Adolescence, 35, 474-484.

Massey, D., \& Denton, N. (1993). American apartheid: Segregation and the making of the underclass. Cambridge, MA: Harvard University Press.

Masten, A. (2001). Ordinary magic: Resilience processes in development. American Psychologist, 56, 227-238.

Matthews, J., Kizzie, K., Rowley, S., \& Cortina, K. (2010). African Americans and boys: Understanding the literacy gap, tracing academic trajectories, and evaluating the role of learning-related skills. Journal of Educational Psychology, 102, 757-771.

McMahon, S., Wernsman, J., \& Parnes, B. (2006). Understanding prosocial behavior: The impact of empathy and gender among African American adolescents. Journal of Adolescent Health, 39, 135-137.

Mello, Z., \& Swanson, D. (2007). Gender differences in African American adolescents' personal, educational, and occupational expectations and perceptions of neighborhood quality. Journal of Black Psychology, 33, 150-168.

Moore, L. V., \& Diez Rouz, A. V. (2006). Associations of neighborhood characteristics with the location and type of food stores. American Journal of Public Health, 96, 325-331.

Murry, V., Berkel, C., Brody, G., Chen, Y., \& Miller, S. (2009). Linking parental socialization to interpersonal protective processes, academic self-presentation, and expectations among rural African American youth. Cultural Diversity and Ethnic Minority Psychology, 15, 1-10.

Nebbitt, V. (2009). Self-efficacy in African American adolescent males living in urban public housing. Journal of Black Psychology, 35, 295-316.

Nebbitt, V., \& Lombe, M. (2008). Assessing the moderating effects of depressive symptoms on antisocial behavior among urban youth in public housing. Child and Adolescent Social Work Journal, 25, 409-424.

Neblett, J., Jr., Chavous, T., Nguyên, H., \& Sellers, R. (2009). "Say it loud-I'm African American and I'm proud": Parents' messages about race, racial discrimination, and academic achievement in African American boys. Journal of Negro Education, 78, 246-259.

New York Civil Liberties Union. (2012). Stop and frisk 2011. Retrieved August 3, 2012, from http://www.nyclu.org/files/publications/NYCLU 2011 Stop-and-Frisk Report.pdf

Olive, E. (2003). The African American child and positive youth development. In F. A. Villarruel, D. F. Perkins, L. M. Borden, \& J. G. Keith, (Eds.), Community youth development: Programs, policies, and practices. Thousand Oaks, CA: Sage Publications.

Phelps, E., Zimmerman, S., Warren, A., Jelicic, H., von Eye, A., \& Lerner, R. (2009). The structure and developmental course of positive youth development (PYD) in early adolescence: Implications for theory and practice. Journal of Applied Developmental Psychology, 30, 571-584.

Phinney, J. (1992). The multigroup ethnic identity measure: A new scale for use with adolescents and young adults from diverse groups. Journal of Adolescent Research, 7, 156-176. 
Plescia, M., \& Herrick, H. (2008). Improving health behaviors in an African American community: The Charlotte racial and ethnic approaches to community health project. American Journal of Public Health, 98, 1678-1684.

Poe-Yamagata, E., \& Jones, M. (2003). And justice for some. Washington, DC: Building Blocks for Youth Initiative.

Portes, A., \& MacLeod, D. (1996). Educational progress of children and immigrants: The roles of class, ethnicity, and school context. Sociology of Education, 69, 255-275.

Prelow, H., Bowman, M., \& Weaver, S. (2007). Predictors of psychosocial well-being in urban African American and European American youth: The role of ecological factors. Journal of Youth and Adolescence, 36, 543-553.

Quillian, L. (2002). Why is black-white residential segregation so persistent?: Evidence on three theories from migration data. Social Science Research, 31, 197-229.

Roberts, S., Lewis, R., \& Carmack, C. (2011). Positive youth development among African American adolescents: Examining single parents as a factor. Journal of Prevention and Intervention in the Community, 39, 310-319.

Robertson, J. (2004). An investigation of the role of racial socialization and racial identity development in the academic achievement and psychological well-being of African American youth. Dissertation Abstracts International, Section B: The Sciences and Engineering, 64(12-B), 6340.

Rodriguez, J., Umaña-Taylor, A., Smith, E., \& Johnson, D. (2009). Cultural processes in parenting and youth outcomes: Examining a model of racial-ethnic socialization and identity in diverse populations. Cultural Diversity and Ethnic Minority Psychology, 15, 106-111.

Rozie-Battle, J. (2002). Youth development: A positive strategy for African American youth. Journal of Health and Social Policy, 15, 13-23.

Sabol, W., West, H., \& Cooper, M. (2010). Prisoners in 2008. NCJ: No. 228417. Available at http://www.bjs.gov/content/pub/pdf/p08.pdf

Scales, P., Benson, P., Leffert, N., \& Blyth, D. (2000). Contribution of developmental assets to the prediction of thriving among adolescents. Applied Developmental Science, 4, 27-46.

Scales, P., \& Leffert, N. (1999). Developmental assets: A synthesis of the scientific research on adolescent development. Minneapolis, MN: Search Institute.

Schmid, C. (2012). The value "social responsibility" as a motivating factor for adolescents' readiness to participate in different types of political actions, and its socialization in parent and peer contexts. Journal of Adolescence, 35, 533-547.

Schneider, M., \& Logan, J. (1982). The effects of local government finances on community growth rates. Urban Affairs Review, 18, 91-105. 
Schott Foundation. (2008). Given half a chance: The Schott 50-state report on public education and Black males. Cambridge, MA: Schott Foundation for Public Education.

Seaton, E., \& Yip, T. (2009). School and neighborhood contexts, perceptions of racial discrimination, and psychological well-being among African American adolescents. Journal of Youth and Adolescence, 38, 153-163.

Sellers, R., Smith, M., Shelton, N., Rowley, S., \& Chavous, T. (1998). Multidimensional model of racial identity: A reconceptualization of African American racial identity. Personality and Social Psychology Review, 2, 18-39.

Sesma, A., \& Roehlkepartain, E. (2003). Unique strengths, shared strengths: Developmental assets among youth of color. Search Institute Insights and Evidence, 1, 1-13.

Settles, I., Navarrete, C., Pagano, S., Abdou, C., \& Sidanius, J. (2010). Racial identity and depression among African American women. Cultural Diversity and Ethnic Minority Psychology, 16, 248-255.

Shah, S. (2011). Building transformative youth leadership: Data on the impacts of youth organizing. Occasional papers series on youth organizing number 11. Brooklyn, NY: Funders' Collaborative on Youth Organizing.

Shaver, P., \& Mikulincer, M. (2011). Attachment theory. In P. A. Van Lange, A. W. Kruglanski, \& E. T. Higgins, (Eds.), The handbook of theories of social psychology: Volume Two, 2 (pp. 160-179). Thousand Oaks, CA: Sage Publications.

Sherrod, L., Flanagan, C., \& Youniss, J. (2002). Dimensions of citizenship and opportunities for youth development: The what, why, when, where, and who of citizenship development. Applied Developmental Science, 6, 264-272.

Skiba, R. (2001). When is disproportionality discrimination? The overrepresentation of African American students in school suspension. In W. Ayers, B. Dohrn, \& R. Ayers, (Eds.), Zero tolerance: Resisting the drive for punishment in our schools (pp. 176-187). New York, NY: The New Press.

Smalls, C. (2009). African American adolescent engagement in the classroom and beyond: The roles of mother's racial socialization and democratic-involved parenting. Journal of Youth and Adolescence, 38, 204-213.

Smalls, C., White, R., Chavous, T., \& Sellers, R. (2007). Racial ideological beliefs and racial discrimination experiences as predictors of academic engagement among African American adolescents. Journal of Black Psychology, 33, 299-330.

Snowden, L., Hastings, J., \& Alvidrez, J. (2009). Overrepresentation of Black Americans in psychiatric inpatient care. Psychiatric Services, 60, 779-785.

Somers, C., Owens, D., \& Piliawsky, M. (2008). Individual and social factors related to urban African American adolescents' school performance. The High School Journal, 91, 1-11.

Staples, R. (1985). Changes in black family structure: The conflict between family ideology and structural conditions. Journal of Marriage and Family, 47, 1005-1013.

Steele, S. (2008). Obama's post-racial promise. The Los Angeles Times. November 5, 2008. 
Stets, J., \& Burke, P. (2000). Identity theory and social identity theory. Social Psychology Quarterly, 63, 224-237.

Swanson, D., Spencer, M., Dell'Angelo, T., Harpalani, V., \& Spencer, T. (2002). Identity processes and the positive youth development of African Americans: An explanatory framework. New Directions for Youth Development, 95, 73-99.

Sweet, E. (2010). "If your shoes are raggedy you get talked about": Symbolic and material dimensions of adolescent social status and health. Social Science \& Medicine, 70, 2029-2035.

Swinton, A., Kurtz-Costes, B., Rowley, S., \& Okeke-Adeyanju, N. (2011). A longitudinal examination of African American attributions about achievement outcomes. Child Development, 82, 1486-1500.

Taylor, C. S., Smith, P. R., Taylor, V. A., von Eye, A., Lerner, R. M., Balsano, A. B. ... Almerigi, J. B. (2005). Individual and ecological assets and thriving among African American adolescent male gang and community-based organization members: A report from wave 3 of the "overcoming the odds" study. The Journal of Early Adolescence, 25, 72-93. doi:10.1177/0272431604271771

Toldson, I. (2008). Breaking barriers: Plotting the path to academic success for school-age African American men. Washington, DC: Congressional African American Caucus Foundation.

Torres-Fleming, A., Valdes, P., \& Pillal, S. (2011). 2010 youth organizing field scan. Brooklyn, NY: Funders Collaborative on Youth Organizing.

Trask-Tate, A., Cunningham, M., \& Lang-DeGrange, L. (2010). The importance of family: The impact of social support on symptoms of psychological distress in African American girls. Research in Human Development, 7, 164-182.

Travis, R. (2013). Rap music and the empowerment of today's youth: Evidence in everyday music listening, music therapy, and commercial rap music. Child and Adolescent Social Work Journal, 30, 139167. doi:10.1007/s10560-012-0285-x

Travis, R., \& Bowman, S. (2012). Ethnic identity, self-esteem and variability in perceptions of rap music's empowering and risky influences. Journal of Youth Studies, 15, 455-478.

doi:10.1080/13676261.2012.663898

Van Ryzin, M., \& Leve, L. (2012). Affiliation with delinquent peers as a mediator of the effects of multidimensional treatment foster care for delinquent girls. Journal of Consulting and Clinical Psychology, 80, 588-596. doi:10.1037/a0027336

Wagaman, M. (2011). Social empathy as a framework for adolescent empowerment. Journal of Social Service Research, 37, 278-293.

Waites, C. (2009). Building on strengths: Intergenerational practice with African American families. Social Work, 14, 278-287.

Wallace, S. (2002). Cultural resilience: An examination of parent, peer, and cultural factors associated with African American teenage attitudes toward delinquency and substance use. Dissertation Abstracts International, Section B: The Sciences and Engineering, 63(3-B), 1592. 
Walton, G., \& Cohen, G. (2011). Brief social-belonging intervention improves academic and health outcomes of minority students. Science, 331, 1447-1451.

Ward, J. (1995). Cultivating a morality of care in African American adolescents: A culture-based model of violence prevention. Harvard Educational Review, 65, 175-188.

Washington, G., \& Johnson, T. (2012). Positive manhood development: A look at approaches and concerns from the frontline. Journal of Human Behavior in the Social Environment, 22, 172-187.

Watts, R., \& Guessous, O. (2006). Sociopolitical development: The missing link in research and policy on adolescents. In S. Ginwright, P. Noguera, \& J. Cammarota (Eds.), Beyond resistance: Youth activism and community change. New York, NY: Routledge, Taylor \& Francis Group.

West, C. (2004). Democracy matters. New York, NY: The Penguin Press.

Whaley, A. (2001). Cultural mistrust: An important psychological construct for diagnosis and treatment of African Americans. Professional Psychology: Research and Practice, 32, 555-562.

Wiggan, G. (2007). Race, school achievement, and educational inequality: Toward a student-based inquiry perspective. Review of Educational Research, 77, 310-333.

Wilson, D., Foster, J., Anderson, S., \& Mance, G. (2009). Racial socialization's moderating effect between poverty stress and psychological symptoms for African American youth. Journal of African American Psychology, 35, 102-124.

Wilson, H., Woods, B., Emerson, E., \& Donenberg, G. (2012). Patterns of violence exposure and sexual risk in low-income, urban African American girls. Psychology of Violence, 2, 194-207.

doi:10.1037/a0027265

Wilson, W. J. (1987). The truly disadvantaged: The inner city, the underclass, and public policy. Chicago, IL: University of Chicago Press.

Wimberly, G. (2002). School relationships foster success for African American students. Iowa City, IA: ACT, Inc.

Wolfer, R., Cortina, K., \& Baumert, J. (2012). Embeddedness and empathy: How the social network shapes adolescents' social understanding. Journal of Adolescence, 35, 1295-1305.

Wood, D., Kaplan, R., \& McLoyd, V. (2007). Gender differences in the educational expectations of urban, low-income African American youth: The role of parents and the school. Journal of Youth and Adolescence, 36, 417-427.

Yancey, A., Grant, D., Kurosky, S., Kravitz-Wirtz, N., \& Mistry, R. (2011). Role modeling, risk, and resilience in California adolescents. Journal of Adolescent Health, 48, 36-43.

Yeager, D. \& Walton, G. (2011). Social-psychological interventions in education: They're not magic. Review of Educational Research, 81, 267-301. 
Zaff, J., Boyd, M., Li, Y., Lerner, J., \& Lerner, R. (2010). Active and engaged citizenship: Multi-group and longitudinal factorial analysis of an integrated construct of civic engagement. Journal of Youth and Adolescence, 39, 736-750.

Zaff, J., Malanchuk, O., \& Eccles, J. (2008). Predicting positive citizenship from adolescence to young adulthood: The effects of a civic context. Applied Developmental Science, 12, 38-53. 
Table 1. Recursive Processes and Bivariate Correlations Among Five C Constructs of Positive Youth Development Reflected in Empirical Research

\section{Recursive Processes and} Correlations

\section{Study}

\section{Moral identity}

Connection to character

Hurd et al. (2009)

Wallace ( 2002)

Yancey et al. ( 2011)

Connection to caring

Decety ( 2011)

Humphries, Parker, and Jagers ( 2000)

Shaver and Mikulincer ( 2011)

Wolfer et al. (2012)

Caring to character

Belgrave et al. (2011)

Humphries and Jagers (2009)

Humphries et al. ( 2000 )

McMahon, Wernsman, and Parnes (2006)

\section{Mastery}

Connection to confidence

Cunningham and Swanson ( 2010)

Gaylord-Harden et al. ( 2007)

Trask-Tate et al. ( 2010)

Connection to competence

Bailey and Bradbury-Bailey (2010) Cunningham and

Brown, Maxwell, DeJesus, and Schiraldi (Swanson (2010)

2002)

Langenkamp (2010)

Denson ( 2003)

Lee et al. (2011)

Gibbs and Bankhead (2000)

Livingston and Nahimana

Hanlon, Simon, O'Grady,

Carswell, and Callaman ( 2009)

Hurd et al. ( 2009)

(2006)

Mello and Swanson

Roberts, Lewis, and Carmack ( 2011)

(2007)

Somers, Owens, and Piliawsky ( 2008)

Prelow et al. (2007)

Toldson ( 2008)

Scales and Leffert (1999)

Wood, Kaplan, and

McLoyd (2007)

Confidence to competence

Murry, Berkel, Brody, Chen, and Miller ( 2009)

Toldson ( 2008)

Gibbs and Bankhead

Chavous et al. (2008)

Clark et al. ( 2005)

(2000)

Swanson et al. (2002)

Walton and Cohen (2011)

Wimberly (2002)

Wood et al. (2007)

Bridging constructs: Moral ID and Mastery

Confidence to character

Nebbitt (2009)

Competence to caring

Martinez, Penaloza, and Valenzuela (

2012)

Wolfer et al. ( 2012)

Note: Sources referenced in the text are italicized. 
Table 2. Recursive Processes and Bivariate Correlations Among Sense of Community and Active and Engaged Citizenship as Culturally Relevant Constructs of Positive Youth Development Reflected in Empirical Research

\section{Recursive processes and Study correlations}

\section{A moral community}

Sense of community to connection

Sense of community to character

Sense of community to caring

\section{A masterful community}

Sense of community to competence

Sense of community and confidence 2009)

Schmid ( 2012)

Wallace ( 2002)

2009)

Ward ( 1995 )

Wolfer et al. ( 2012)

Barrow et al. (2007)

Brown et al. ( 2009 )

)

Murry et al. ( 2009 )
Brown, Linver, Evans, and DeGennaro (

Gaylord-Harden et al. ( 2007 )

Hart, Atkins, and Ford ( 1998 )

Humphries et al. ( 2000 )

Wilson, Foster, Anderson, and Mance (

Neblett, Chavous, Nguyên, and Sellers ( 2009 )

Kerpelman, Eryigit, and Stephens ( 2008 Robertson ( 2004 )

Davis and Stevenson ( 2006 )

Gaylord-Harden et al. ( 2007 )

Hughes et al. ( 2009)

Mandara, Gaylord-Harden, Richards, and Ragsdale (2009)

Plescia and Herrick ( 2008 )

Rodriguez, Umaña-Taylor,

Smith, and Johnson ( 2009)

Rozie-Battle ( 2002 )

\section{Active and engaged citizenship}

Community and citizenship

Crocetti, Jahromi, and Meeus ( 2012)

Flanagan and Levine ( 2010 )

Ginwright (2003)

Hart et al. (1998)

Moral identity and citizenship Martinez et al. ( 2012)

Flanagan and Levine ( 2010 )

Mastery and citizenship
Smalls ( 2009)

Walton and Cohen ( 2011 )

Seaton and Yip ( 2009)

Taylor et al. ( 2005 )

Travis and Bowman ( 2012 )

Waites ( 2009)

Walton and Cohen ( 2011 ) Washington and Johnson ( 2012)

Kirshner, Strobel, and Fernandez ( 2003) Sherrod, Flanagan, and Youniss ( 2002) Travis and Bowman ( 2012 ) Waites ( 2009)
Crocetti et al. ( 2012 )

Flanagan and Levine ( 2010 )

Martinez et al. ( 2012)

Watts and Guessous ( 2006 ) 
Note: Sources referenced in the text are italicized. 
Figure 1. Structural model of the Five Cs of Positive youth development (PYD). Adapted from Bowers et al. (2010).

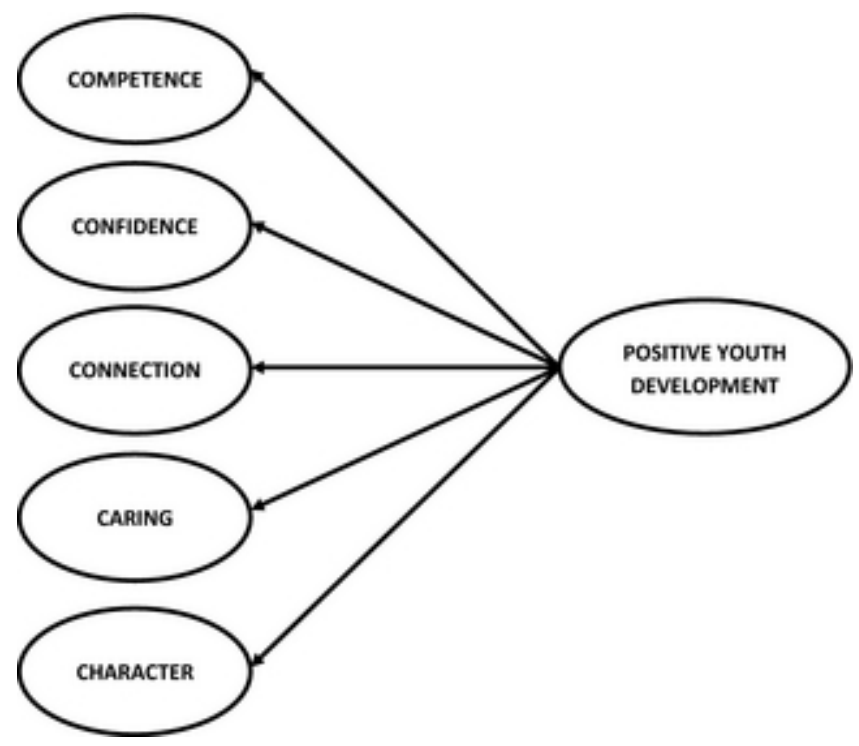


Figure 2. Recursive pathway models in seven $C$ empowerment-based positive youth development model.
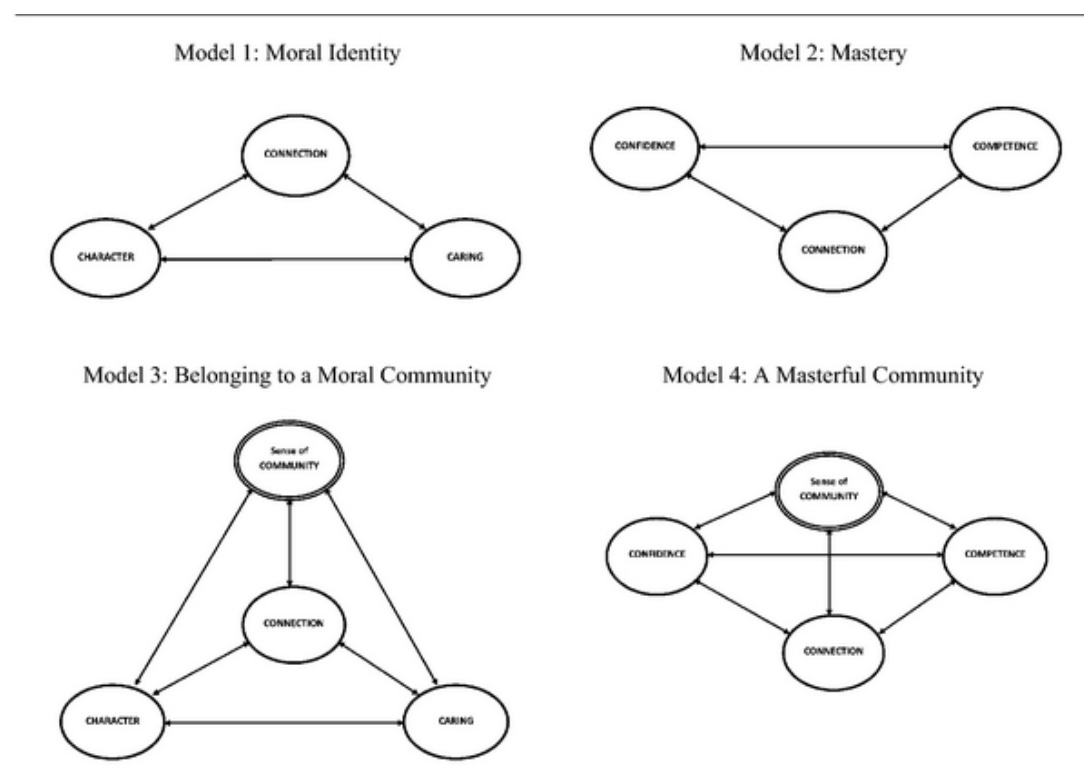

Model 4: A Masterful Community

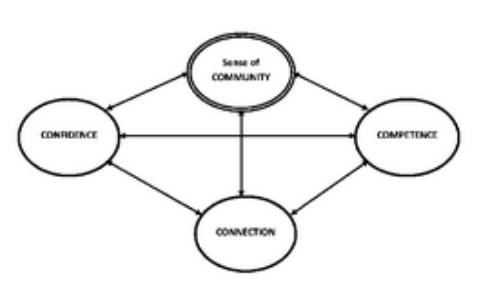

Model 5: Connection, Belonging and Citizenship as Anchors of Moral and Masterful Communities

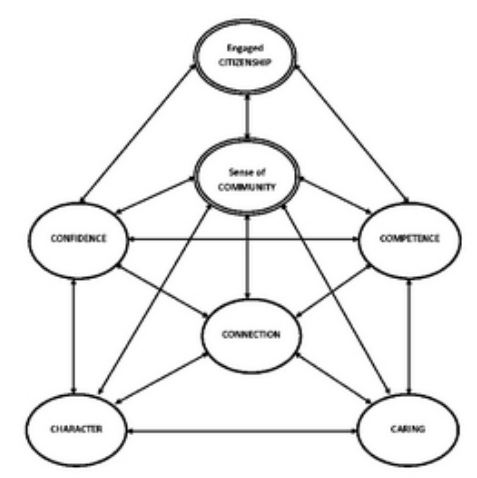

